\title{
PROGRAM KEMITRAAN MASYARAKAT (PKM) PENINGKATAN KUALITAS HIDUP PASIEN THALASEMIA DI KABUPATEN JOMBANG
}

\author{
Community Partnership Program (Pkm) Improving Life Quality Of Thalasemic Patients \\ In Jombang District
}

\author{
${ }^{1}$ Ana Farida Ulfa, ${ }^{1}$ Pujiani, ${ }^{1}$ Edi Wibowo \\ ${ }^{1}$ Fakultas Ilmu Kesehatan, Universitas Pesantren Tinggi Darul Ulum Jombang \\ Email: anafaridaulfa@fik.unipdu.ac.id
}

\begin{abstract}
Abstrak
Tujuan Program Kemitraan Masyarakat ini adalah meningkatkan kualitas hidup pasien thalasemia di akabupaten Jombang. Seperti kita ketahui bersama thalasemia merupakan penyakit kronis yang memiliki dampak sangat komplek dalam kehidupannya. Tidak hanya aspek biologis, tetapi juga pada aspek psikologis dan sosial. Jumlah anak dengan thalasemia di Kabupaten Jombang yang terdaftar menjalani tranfusi rutin di RSUD Jombang adalah 27 anak, dan sekitara ada sekiatr 10 anak yang menjalani transfusi rutin di RSUD dr. Soetomo Surabaya. Selama ini dukungan yang didaptkan oleh anak-anak thalasemia adalah sebatas pada permasalahan fisik. Sementara terkait masalah psikologi dan sosial seperti harga diri rendah, ketidakmampuan mengikuti pendidikan seperti anak-anak yang sehat, dan adanya putus sekolah belum mendapat perhatian baik dari pemerintah maupun dari masyarakat secara umum. Metode yang digunakan dalam program kemitraan masyarakat ini adalah dengan kegiatan pendampingan, seminar / parenting, terapi aktifitas kelompok untuk mengatasi masalah bio-psiko-sosio dan spiritual. Pelaksanaaan kegiatan dilakukan dimasyarakat di desa Kwaron Diwek, FIK Unipdu Jombang dan RSUD Jombang.
\end{abstract}

Kata kunci : Kualitas Hidup, Thalasemia

\begin{abstract}
The aim of the Community Partnership Program is to improve the quality of life of thalassemia patients in the district of Jombang. As we all know, thalassemia is a chronic disease that has a very complex impact in life. Not only biological aspects, but also psychological and social aspects. The number of children with thalassemia in Jombang District who were registered to undergo routine transfusion in Jombang District Hospital were 27 children, and there were approximately 10 children who underwent routine transfusion in the dr. Soetomo Surabaya. During this time the support received by thalassemia children is limited to physical problems. While related to psychological and social problems such as low self-esteem, inability to attend education such as healthy children, and the absence of school dropouts have not received attention from the government or the general public. The method used in this community partnership program is through mentoring, seminar / parenting activities, group activity therapy to overcome bio-psycho-socio and spiritual problems. The implementation of the activities was carried out in the community in the villages of Kwaron Diwek, FIK Unipdu Jombang and RSUD Jombang.
\end{abstract}

Keywords: quality of life, thalassemia

\section{A. PENDAHULUAN}

Talasemia merupakan penyakit kronis yang menjadi masalah kesehatan masyarakat serius di dunia. Kompleksitas permasalahan pada penderita talasemia sepertinya tidak hanya menyangkut aspek biologis tetapi juga aspek psikologis, sosial, dan spiritual. Karena itu penderita talasemia dituntut memiliki kemampuan menyesuaikan diri yang baik agar mampu mempertahankan hidup dan melangsungkan kehidupannya.

Hasil wawancara dengan paguyuban orang tua penderita thalasemia mengungkapkan bahwa permasalahan yang mereka hadapi adalah belum adanya dukungan pada aspek psikologis dan sosial, pada aspek psikologis keluarga 
sering kali merasa jenuh dengan rutinitas transfusi, keluarga dengan anak yang menderita talasemia menggambarkan bahwa mereka mengalami proses berduka yang berulang terkait diagnosa yang talasemia yang dialami anaknya, sering kali keluarga kembali ke tahap penolakan atau denial saat harus membawa anaknya kembali ke rumah sakit untuk mendapatkan transfusi. Pada aspek sosial sebanyak 5 responden ( $100 \%$ ) orang tua mengeluhkan kasian dengan anaknya yang tidak bisa beraktivitas seperti teman sebayanya. Dilihat dari tingkat pendidikan pasien thalasemia yang ada di Jombang pendidikan tertinggi hanya sampai SLTP, bahkan beberapa pasien hanya sampai tingkat SD dengan alasan tidak mampu mengikuti pembelajaran dengan baik, dan selama ini paguyuban belum bisa mengadakan kegiatan untuk pasien thalasemia, agar bakat dan minat pasien-pasien tersebut dapat dikembangkan.

Keluhan yang disampaikan kelompok pasien thalasemia pada aspek psikologis adalah mereka merasa jenuh dengan kegiatan transfuse yang harus dilakukan, selain pasien juga merasa pelayanan di rumah sakit saat trnsfusi kurang care, pasien merasa takut dan enggan setiap kali harus ke rumah sakit, stigma yang ada pada pasien adalah petugas kesehatan jahat dan mudah marah bila pasein melakukan kesalahan. Selama ini perawatan pasien thalasemia hanya fokus pada aspek fisik, belum pernah menyentuh aspek psikologis, padahal anak-anak thalasemia juga membutuhkan dukungan psikologis agar tetap semangat menjalani transfuse secara rutin, memiliki semangat untuk bertahan hidup.

Peran masyarakat sipil dalam hal ini perguruan tinggi perlu perhatian yang lebih besar untuk mendorong upaya peningkatan kualiatas hidup pada anak thalasemia, khususnya pada aspek psikologis, sehingga mereka memiliki kesempatan yang sama dengan anak sehat lainnya untuk berkembang dan memiliki kualitas hidup yang baik.

Melihat paradigma yang terjadi pada anak dengan thalasemia, maka Fakultas Ilmu Kesehatan Unipdu Jombang dalam Tim Pengabdian masyarakat merasa perlu untuk berperan serta dalam berbagai upaya untuk meningkatkan kualitias hidup anak thalasemia.

Upaya pertama yang dilakukan antara lain dengan mengaktifkan paguyuban orang tua penderita thalasemia untuk memberikan support yang terus menerus yang nantinya akan bekerja sama dengan FIK Unipdu Jombang. Kerja sama yang ditingkatkan adalh dengan melibatkan perawat anak khususnya di RSUD Jombang, melibatkan Dinas Sosial khususnya dalam bidang pendampingan dalam pemenuhan hak- anak. Selanjutnya semua tim dan masyarkat yang terlibat akan bahu membahu melakukan berbagai bentuk kegiatan untuk anak thalasemia secara komprehensif baik upaya preventif, promotif, kuratif, dan rehabilitatif dengan pendekatan yang lebih holistik bio-psiko-sosial- dan spiritual.

\section{A. PELAKSANAAN DAN METODE}

Berdasarkan permasalahan di atas, agar terjadi sinergi antara paguyuban orang tua penderita thalasemia, perawat anak, Dinas Sosial, dan tokoh masyarakat di desa wilayah kecamatan Jombang dengan FIK Unipdu, maka FIK Unipdu membentuk kelompok sebaya ( peer group ) thalasemia. Kelompok sebaya ( peer group ) thalasemia inilah yang akan menjadi wadah dalam upaya meningkatkan kualitas hidup pasien thalasmeia kabupaten Jombang.

Adapun solusi yang direncanakan dan 
dilaksanakan berdasarkan prioritas dari masalah mitra adalah: yang pertama terdapat masalah kurangnya sentuhan biopsikososio-spiritual bagi anak thalasemia. Selama ini dukungan yang sudah sangat baik diberikan adalah dalam aspek fisik atau biologis yaitu pemberian transfusi rutin di RSUD Jombang. Sedangakan pada aspek sosial dan psikologis baik anak thalasemia maupun keluarga belum mendapatkan dukungan secara khusus dan kontinu. Kegiatan yang dilakukan adalah membentuk kelompok sebaya ( peer group ) thalasmeia. Tujuan dari pembetukan kelompok sebaya ( peer group ) ini adalah untuk meningkatkan support system diantara pasien thalasemia sehingga mereka memiliki semangat yang tinggi untuk bertahan dan patuh pada perawatan. Kegiatan lainnya yaitu melakukan parenting pada orang tua penederita thalasemia, memberikan dukungan dan pendampingan kepada keluarga dengan anak thalasemia agar meraka dapat mandiri dalam melakukan perawatan pada anak thalasmeia, khususnya perawatan di rumah, sehingga anak thalasemia mendapatkan hak- haknya dengan baik. Memberikan terapi aktivitas kelompok sosialisasi untuk meningkatakn kemampuan anak-anak thalasemia bersosialisasi. Kegiatan out bond bersama keluarga besar thalasemia Jombang juga dilakukan sebagai upaya meningkatkan keakraban diantara anak thalasemia dan keluarga.

Kegiatan ini juga bertujuan untuk meningkatkan harga diri anak-anak thalasemia. Seminar tentang thalasemia juga dilakukan untuk meningkatan pengetahuan masyarakat tentang thalasemia, sehingga masyarakat lebih peduli dengan keberadaan anak-anak thalasemia yang ada disekitarnya.

Kedua, terdapat permasalahan kurangnya peran serta dari tenaga kesehatan dan masyarakat pada umumnya dalam memberikan dukungan kepada anak-anak thalasemia dan keluarga, khususnya secara psikologis dan sosial. Untuk mengatasi permaslaahan ini tim PKM bekerja sama dengan departemen jiwa di FIK Unipdu Jombang, Departemen Anak FIK Unipdu Jombang, Dinas Sosial Kabupaten Jombang khususnya bidang rehabilitasi dan pelayanan sosia, dan perawat anak di RSUD Jombang. Kami juga menggandeng elemen masyarakat lainnya, misalnay dosen di Fakultas Pendidikan, relawan mahasiswa untuk ikut serta dalam kegiatan pengabdian masyarakat ini dalam wadah Forum Peduli Thalasemia Kabupaten Jombang. Harapan kami forum ini akan dapat menjadi patner bagi paguyuban orang tua penderita thalasemia untuk memberikan pelayanan yang baik bagi anak-anak thalasemia.

Ketiga, permasalahan yang muncul adalah wadah yang dapat memeberikan supportif edukatif dalam pengembangan bakat dan minat. Selama ini beberapa anak thalasemia terpaksa harus berhenti sekolah setelah lulus SD atau SLTP karena merasa fisiknya tidak mampu untuk mengikuti proses pembelajaran di sekolah. Sehingga mereka tidak memiliki kegiatan untuk mengisi kesehariannya. Kegiatan yang dilakukan untuk mengatasi masalah ini adalah dengan memberikan terapi aktivitas kelompok, ketrampilan membuat bros.

\section{Metode pendekatan yang ditawarkan untuk menyelesaikan persoalan mitra :}

Permasalahan mitra terutama pada dukungan aspek spikologis, spiritual dan soasil untuk keluarga thalasemia dalam melakukan perawatan thalasemia. Permasalahan ini terjadi karena kurangnya belum adanya wadah khusus bagi pasien thalasemia ataupun keluarga untuk 
mendapatkan dukungan secara luas dari masyarakat, selama ini dukungan hanya dalam aspek fisik, yaitu perawatan di rumah sakit dan transfusi rutin. Pendekatan tang ditawarkan tim PKM dalam kegiatan pengabdian masyarakat ini meliputi:

1. Sosialisasi program PKM

Sosialisasi program dilakukan untuk mengenalkan program dan tim kepada kelompok keluarga dan pasien thalasemia serta pihak yang terkait, mislanya perawat anak dan dinas sosial. Dalam tahapan ini sekaligus disepakati tentang komitmen untuk melaksanakan program PKM sampai tuntas.

2. Membentuk kelompok sebaya ( peer group ) penderita thalasemia kabupaten Jombang.

Kelompok sebaya bertujuan untuk meningkatkan koping anak-anak thalasemia dnegan mendapatkan dukungan dari sesama pasien.

3. Seminar kesehatan

Seminar ini bertujuan agar keluarga thalasemia dan masyarakat dapat meningkatkan pengetahuan sehingga mampu memberikan perawatan thalasemia di rumah.

4. Terapi Aktivitas Kelompok dan pendampingan.

Terapi aktivitas kelompok bertujuan untuk meningkatkan dukungan sosial kepada anak thalasemia dan memberikan kegiatan yang bersifat refreshing kepada anak thalasemia dan sesuai dengan kondisi fisik anak thalasemia.

5. Pelatihan relaksasi spiritual

Pelatihan ini bertujuan dapat meningkakan kemampuan keluarga dan pasien dalam melakukan terapi untuk anak-anak thalasemia dari aspek spiritual

6. Evaluasi dan monitoring

Program dimonitoring dan dievaluasi dengan cara kualitatif dan pengukuran kuantitatif untuk mengukur peningkatan pengetahuan, sikap, perilaku, dan keberhasilan program.

\section{B. HASIL DAN PEMBAHASAN}

Kegiatan pengabdian kepada masyarakat ini mulai pada tangaal 2 Februari 2018 dengan langkahlangkah:

(1) persiapan dan membuat perencanaan kegiatan; (2) pelaksanaan kegiatan pengabdian masyarakat dan (3) Rencana tindak lanjut. Pada tahap persiapan, melakukan koordinasi dengan tim pengabmas untuk menyusun rencana agenda kegiatan pengabdian masyarakat pada anak thalasemia selama satu tahun. Selanjutnya melakukan koordinasi dengan tim dari Fakultas, ketua paguyuban orang tua penderita thalasemia Kabupaten Jombang, perawat anak RSUD Jombang, Dinas Sosial Kabupaten Jombang khususnya bidang pelayanan dan rehabilitasi sosial. Dari hasil studi dokumentasi di RSUD Jombang dan dilapangan ditemukan jumlah penderita thalasemia di Kabupaten Jombang sekitar

37 anak. Sebanyak 27 anak thalasemia melakukan transfusi rutin di RSUD Jombang dan 10 lainnya melakukan tranfusi rutin di RSUD dr. Soetomo Surabaya. Data ini belum kami anggap valid karena ada kemungkinan anak thalasemia yang tranfusi di $\mathrm{dr}$ Soetomo Surabaya masih ada yang belum terekap. Jumlah kasus tertinggi kejadian thalasemia di kabupaten Jombang berada di Kecamatan Diwek, Jombang. Oleh karena itu fokus pelaksananan untuk kegiatan Program Kemitraan Masyarakat untuk meningkatkan kualitas hidup pasien thalasemia adalah di Desa Kwaron, Kecamatan Diwek, Kabupaten Jombang.

Pada tahap persiapan dan koordinasi ini semua elemen yang sudah kami sebutkan di atas mendukung penuh dan bersedia untuk menjadi tim dalam pelaksanaan kegiatan pengabmas ini. 
Bahkan tim sepakat kedepan akan dibentuk forum peduli thalasemia kabupaten Jombang yang dilegalkan oleh Kesbangpol Jombang. Berdasarkan hasil koordinasi yang kami lakukan secara garis besar program kegiatan pengabmas ini meliputi : program peningkatan peran keluarga dlaam perawatan anak thalasemia, program peningkatan peran serta tenaga kesehatan dan masyarakat dalam meningkatkan kulitas hidup pasien thalasemia, program peningkatan bakat dan minat anak thalasemia. Tahap selanjutnya yang kami lakukan adalah melakukan sosialisasi terkait program kegiatan pengambas dalam satu tahun melalui foruk paguyuban orang tua penderita thalasemia.

Selanjutnya pada tahap kedua yaitu pelaksanaan kegiatan. Program yang dilaksanakan pertama kali adalah upaya untuk meningkatkan peran serta masyarakat dalam meningkatkan kualitas hidup pasien thalasemia, untuk itu dimulai dengan pembentukan kelompok sebaya (peer group) thalasemia yang dilaksanakan bersamaan dengan kegiatan parenting untuk keluarga thalasemia. Kegiatan ini dilaksanakan pada tanggal 14 Maret 2018 di RSUD Jombang. Dengan adanya kelompok sebaya (peer group) thalasemia diharapkan menjadi wadah bagi tenaga kesehatan dan masyarakat untuk memberikan support dan pendampingan langsung kepada anak thalasemia.

Dalam kegiatan parenting keluarga, keluarga menyampaikan mendukung penuh terhadap kegiatan program pengabmas yang dilakukan dalam kurun waktu satu tahun. Sedangkan untuk pembentukan kelompok sebaya ( peer group ) thalasemia, disepakati ketua kelompok sebaya ( peer group ) thalasemia adalah Atik Nur ( pasien thalasemia dari Wonosalam, Jombang ).
Selain pembentukan kelompok sebaya ( peer group ) thalasemia, bentuk kegiatan untuk memberikan dukungan pada anak thalasemia adalah Terapi Aktivitas Kelompok ( TAK ) sosialisasi yang dilakukan untuk meningkatkan kemandirian sosial anak-anak thalasemia. Berdasarkan hasil evaluasi kegiatan TAK sosialisasi, anak-anak thalasemia menyampaikan menjadi semakin akrab dengan anak thalasemia lainnya dan percaya diri ketika bertemu dengan orang lain. Selain Terapi Aktivitas Kelompok (TAK) Sosialisasi, kegiatan untuk memberikan dukungan kepada anak thalasemia dalam aspek sosial dan psikologi adalah dilaksanakan family gathering untuk keluarga thalasemia di Balai Tani Bareng. Dalam kegiatan ini anak-anak thalasemia melaksanakan out bond bersama. Tujuan dari kegiatan ini adalah untuk meningkatkan kemampuan sosial pada anak thalasemia, kegaitan ini juaga dijadika sebagai sarana refreshing anak-anak thalasemia sehingga mereka bisa merasa bahagia. Selama ini anak-anak thalasemia mengalami keterbatasan dalam melakuka aktifitas sosial sehari-hari, anakanak thalasemia memiliki keterbatasan fisik untuk dapat melakukan aktifitas seperti temannya yang sehat, baik di rumah maupun saat di sekolah. Karena itu, kegiatan out bond diharapkan mampu memberikan dukungan psikologis (kebahagiaan) pada anak-anak thalasemia.

Kegiatan yang mengacu pada program peningkatan peran keluarga dalam merawat pasien thalasmeia adalah kegiatan parenting keluarga, pada tanggal 14 Maret 2018 dilaksanakan di RSUD Jombang, dalam kegiatan ini orang tua mendapatkan support dari perawat anak dan tim pengabmas, keluarga juga mendapat mendampingan dari tim psikolog dinas sosial. Selanjutnya juga diadakan seminar thalasemia yang tidak 
hanya diikuti oleh keluarga thalasemia tapi juga beberapa perangat desa kwaron. Kegiatan ini untuk meningkatkan kemampuan keluarga dalam memberikan perawatan anak thalasemia khususnya di rumah. Selain itu seminarr ini juga akan meningkatkan pemahaman masyarakat tentang thalasemia. Sehingga masyarakat juga bisa memberikan dukungan sosial kepada anak thalasemia. Dalam seminar ini materi yang disampaikan adalah perawatan pada anak thalasemia di rumah dan peran keluarga dalam pemberian perawatan apada anak dengan thalasemia. Selain kegiatan seminar yang diikuti oleh par orang tua dan tohoh masyarakat, di waktu yang bersamaan kami melakukan Terapi Aktivitas Kelompok pada anakanak thalasemia yang dipandu oleh relawan dari Dinas Kesehatan Sosial Kabupaten Jombang. Dalam kegiatan TAK ini anak-anak thalasemia melakukan sosialisasi dengan pasien lain dan eksplorasi terhadap perasaan mereka masing-masing selama sakit dan menjalani perawatan rutin. Anak-anak juga melakukan permainan sederhana sesuia dengan kondisi fisiknya, seperti melipat kertas dan bermain tebak- tebakkan. Kegiatan TAK ini diharapkan dapat meningkatkan kemmapuan sosialisasi anak-anak thalasemia yang pada akhirnya akan meningkatkan harga diri mereka dalam bersosialisasi dengan lingkungannya. Dalam kegiatan ini kami selaku tim PKM juga melakukan penelitian dengan judul pengaruh pola asuh keluarga terhadap harga diri pada anak thalasemai dan sudah dipublikaiskan dalam prosiding seminar inetrnational "The 2nd Joint International Conferences Vol 2 No2 ( 2018 ).

Setelah kegiatan seminar keluarga dan Tim PKM bersama perawat anak RSUD Jombang dengan didampingi psikolog melkaukan diskusi dan curah pendapat terkait permasalahan yang dialami masing- masing keluarga selama merawat thalasemia dan meceritakan solusi yang sduah diupayakan keluarga. Dalam sesi ini keluarga merasa bebannya berkurang karena memiliki kesempatan untuk menyampaikan permasalahan yang selama ini dihadapi dan mendapatkan solusi baik dari psikolog, perawat anak RSUD maupun pengalaman dari keluarga thalasemia lainnya.

Kegiatan lain yang teah dilaksanakan dalam upaya meningkatkan kualitas hidup pasien thalasemia adalah dengan dilaksanakannya pelatihan relaksasi sipritual bagi keluarga thalasemia. Kegiatan ini dilaksanakan pada tanggal 31 Juni 2018 di ruang 102 Fakultas Ilmu Kesehatan Unipdu Jombang. Kegiatan pelatihan terapi relaksasi spiritual diikuti oleh keluarga thalasemia se Jombang dengan jumlah sekiatr 30 keluarga, masing-masing keluarga diperkenankan membawa anggota keluarga lain selaian pasien thalasemia. Tujuan dari kegitan ini adalah meningkatkan kemampuan pasien thalasemia dan keluarga untuk melakukan terapi relaksasi spiritual secara mandiri. Pada kegiatan ini dipandu oleh fasilitator semua peserta belajar untuk melakukan terapi relaksasi spiritual secara mandiri. Sebelum mengikuti terapi peserta diminta untuk menceritakan keluahan-keluhan yang dialami, dan selnajutnya keluahakeluhan tersebut dievaluasi setelah dilakukan terapi relaksasi spiritual. Hasil evaluasi peserta yang bisa mengikuti relaksasi dengan baik menyampaikan bahwa merasa tubuhnya bugar dan segar. Bahkan ada yang menyampaikan keluhan rasa nyerinya hilang. Kegiatan terapi ini tidak hanya dilakukan sekali, namun diulang lagi sekitar 1 bulan kemuadian atas permintaan keluarga yang merasa terapi ini sangat bermanfaat, diantaranya anaknya yang sakit thalasemia tidak mudah lelah setelah aktivitas dan mudah tidur, setelah setiap menjelang tidur dilakukan terapi relaksasi spiritual oleh ibunya. 


\section{PENUTUP}

1. Kesimpulan

Pengabdian kepada masyarakat ini dilakuakn sebagai upaya dalam membantu meningkatkan kualitas hidup pasien thalasemia, khususnya di wilayah Kabupaten Jombang. Kegiatan ini diharapkan mampu meningkatkan dukungan kepada keluarga maupun anak-anak thalasemia dari aspek psikologis, spiritual dan social.

2. Saran

Harapan kami selaku tim pengabdian masyarakat maupun keluarga thalasemia agar kegiatan dalam upaya mendukung keluarga thalasemia khususnya dalam aspek psikologis, spiritual dan sosial ini tidak hanya berhenti sampai disini. Namun ada keberlanjutan kegiatan yang akan semakin memberikan peluang anakanak thalasemia untuk hidup normal seperti anak-anak sehat lainnya.

\section{Daftar Pustaka}

Kluge,C.R., Michael,K., dan Werner, K., 2013. Frequency and Relevance of Psychoeducation in Psychiatric Diagnoses: Result of Two Survey Five Years Apart in GermanSpeakig European Countris. BMC Psychiatri 13 (170).
Marilyn M. Friedman., Bowden, V.R., dan Jones. 2010. Buku Ajar Keperawatan Keluarga Riset Teori dan Praktik. EGC. Jakartatuart, G.W., dan Laraia, M.T. 2005. The Principle And Practice of Psychiatric Nursing. Edisi 8. Elsevier Mosby, st Louis. Missouri.

Orem, D.E. 2001. Nursing Concept of Practiced. St. Louis: the CV Mosby company.

Struart, G.W., dan Laraia, M.T. 2005. The Principle And Practice of Psychiatric Nursing. Edisi 8. Elsevier Mosby, st Louis. Missouri.

Supratiknya, A. 2011. Merancang Program dan Modul Psikoedukasi. Universitas Sanata Darma. Yogyakarta.

Supriyanto,S., Djohan,A. 2011. Metodologi Riset Bisnis Dan Kesehatan. PT Grafika Wangi Kalimantan. Kalimantan.

Tommey, A.M,. dan Alligood, M.R. 2006. Nursing Theory and Their Work. Missouri. Mosby.

Wong, D. L., Marilyn, H.E., David, W., Marilyn, L W., dan Patricia, S. 2009. Buku Ajar Keperawaan Pediatrik. Volume 1. EGC. Jakarta. 